\title{
The application of Audio Articulation Method to rehabilitate/u/ঊ// Sound in tertiary level students of Bangladesh
}

\author{
Mohammad Uddin \\ IIUM, Malaysia \\ nashir.rayhan@gmail.com
}

\section{ARTICLE HISTORY}

Received: 21/12/2021

Accepted: 03/01/2022

\section{KEYWORDS}

Rehabilitation, fossilization, pronunciation error, chain drill, substitution drill, audio-articulation method

\section{Abstract}

The target of this paper incorporates rehabilitation of /u/ sound in Bangladeshi adult speakers of English in classroom practice. The phoneme Iu/ is a short vowel and /u:/, a long vowel in English phonemic inventory. But long and short vowel distinction is not a phonemic feature in Bangla. That is why, many Bengali speakers of English pronounce /u// in both the cases as there is ঊ $\mathrm{Iu} /$ sound in Bengali language. This creates problem for the listeners specifically the native speakers to understand the speech of the Bengali adult speakers of English and the comprehensibility level of their pronunciation is very low. The researcher, from his practical experience, finds that Phonological establishment of ঊ / $u /$ sound in the tertiary level students of Bangladesh is one of the main reasons of this problem. This paper is a pedagogically designed lesson plan to rehabilitate the fossilized /u/ / sound in Bengali speakers by applying Audio Articulation Method in the class hour. By operating various kinds of drills such as, interaction drill, substitution drills, minimal pairs, tongue twister etc in the class hour, the teachers can conduct the class to rehabilitate the fossilized sounds in the learners and both the trainers and trainees in Bangladesh can get the chance to defossilize the fossilized sound by these drillings.

\section{INTRODUCTION}

Pronunciation is a set of habits of producing sounds to make meaning (Gilakjani, 2012). This habit is required by repeating it over and over again and by being corrected if there are any mistakes. Pronunciation includes attention to the particular sounds of language (segmental aspects), aspects of speech such as intonation, stress, phrasing, timing, rhythm (suprasegmental aspects), and others (gesture and expression) that are still related to the way we speak a language (Gilakjani, 2012).

Since English is the major international language, standard pronunciation facilitates greater international intelligibility and acceptability. Language is an art and so has its own artistic aspects. Proper pronunciation is an indispensable aspect of that art ideally fusing correct articulation of sounds, right accentuation, proper rhythm, correct intonation patterns (Joseph, et al., 2019)."The main problem of English pronunciation is to build a new set of boxes (in the mind) corresponding to the sounds of English, and to breakdown the arrangement of boxes which the habits of our native language have so strongly built up."(J. D. O'Connor, 2008). Most of the EFL/ESL students face the problem of producing and pronouncing certain vowels 
and consonants sound as they have lacking in the knowledge of place of articulation, manner of articulation and tongue position in case of producing these sounds.

In the field of language teaching, the role of pronunciation has varied widely from having virtually no role in the grammar-translation method to being the central focus in the audiolingual method where emphasis is on the traditional notions of pronunciation, minimal pairs, drills and short conversations (Castillo, 1990: 3). According to Richards and Rodgers (1986), the situational language teaching, developed in Britain, also reflected the audio-lingual view of the pronunciation class. In the audio-lingual method, "The pronunciation class ... was one that gave primary attention to phonemes and their meaningful contrasts, environmental allophonic variations, and combinatory phonotactic rules, along with ... attention to stress, rhythm, and intonation." (Morley, 1991: 484 as in Pardede, 2010). Demirezen in (2004, 2000) propounded a new method called Audio articulation method which also emphasizes on drilling technique but the primary focus of this method is on the fossilization of distinct sound and the process of defosilization by applying different kinds of drills.

Fossilized error in English pronunciation by the teachers and students is a prevailing phenomenon in Bangladesh. The distinct fossilized features of Bangla frequently intervene in their English speaking (Uddin, 2021). The core sound of English language, VIZ, the vowel u: sound in the word "abuse" /a'bju:z/ is pronounced by the Bengali speakers as /æbuz/ (Amanullah, 2009, p.125) constitutes the major fossilized mistake continuum for Bangladeshi teachers, teacher trainees and students in teaching and learning English as a foreign language. At the same way, the Bengali speakers cannot differentiate between "full" and "fool" as there is no long /u/ in Bengali language and the /u/ উ/ sound has been established in them. A technique of teaching that can be used to improve the mastery ofpronunciation is by using drill technique. A drill is an oral exercise aims to give the students methodical practice of particular syntactic structure which is naturally expressed and easily to remember utterances in target language (Maharida, 2014). According to Broughton et al. (1980:62) the teacher should be prepared to slip a few minutes' pronunciation drill into a lesson at any point where a significant problem is noticed. Audio-Articulation Method mainly emphasizes on this drill technique and the teachers can use different kinds of drills to correct the fossilized pronunciation errors of students in EFL classroom.

\section{STARTING THE CLASS}

\section{Learning objectives:}

Objectives of this lesson?

i. To teach the student the manner and place of articulation of $/ \mathrm{u} / \mathrm{and} / \mathrm{u}$ :/ sound

ii. To help them to produce words with /u/ and /u:/ sound

iii. To identify fossilized errors in their English pronunciation

iv. To help them to defossilize the problem causing sound in their speaking

Teacher: Students, today I am going to discuss the articulation of $/ \mathrm{u} / \mathrm{and} / \mathrm{u}$ :/ sound in such words as full, fool, pull, pool, look, hook (Amanullah, 2009. P, 22) and practice for defossilizing /u/ sound.

Teacher: Ruhul, can you give the definition of /u:/ sound? 
Ruhul: Yes, sir, the [u:] sound of the English language is a long, high, rounded vowel. (Cambridge Dictionary of American English 2000). /u:/ is longer than / /. / $\mathrm{u}: /$ often sounds as a diphthong [uw] or [uw] (https://teflpedia.com/Pronunciation_exercises).

The application of the audio-articulation method will be noticeable in the following way where the problem causing sound like/u:/ phoneme will be treated, and steps will be taken to rehabilitate /u/ sound among the Bangladeshi EFL learners and teachers. This method also helps to communicate orally through pronunciation practices according to the demand of the context.

interaction drill:

Teacher: Dear students read the following dialogues and give special attention to the bold faced words in the dialogues.

\section{Dialogue 1: In a café}

Supervisor: Good afternoon, please have your seat,sir.

Rubel: Good afternoon, please, show us the menu.

Supervisor: Here is the menu.

Rubel: Tutul, what would you like to consume, soup or pudding?

Tutul: I prefer pudding. What will you consume?

Rubel: I like soup. I don't know whether they cook soup or not.

Tutul: Supervisor, do you have soup and pudding?

Supervisor: We regularly cook soup but sometimes, cook pudding.

Tutul: Ok, do you have noodles?

Supervisor: Yes, we frequently cook noodles.

Rubel: Give me a bowl full of soup and give Tutul a bowl full of noodles.

Supervisor: Ok, please, wait for two minutes.

Rubel: Sure.

Supervisor: Here is the soup and noodles.

Rubel: Ok, thank you.

Tutul: How much is the bill? I would like to pay it.

Supervisor: It is one hundred twenty two taka. 
Tutul: Here is two hundred taka.

Supervisor: Ok, here is the seventy eight taka. Thank you.

\section{Tutul : Welcome.}

\section{Teacher:}

Dear learners, it is evident from your speaking that you have mispronounced the English /u:/ phoneme in the words of boldfaces. Of course, there are words containing /u/ sound in the dialogue. Your / $\mathrm{u} / /$ sound is influenced by the /u/ উ,/ phoneme, which prevent you to pronounce it as the native speakers do. It is because, there is /u /উ,/ sound in Bengali language and it has been fossilized in you. We must consider this wrongly pronounced sound. So, we will study on it today. We shall follow different kinds of drills of Audio-Articulation method propounded by Mehmet Demirezen to treat this problem causing sound in the class.

\section{Repetition drill:}

Firstly, T selects a corpus of 50-100 words having the [u] and [u:] sounds. He arranges these words and categorizes them according to four syllabic (mono, di, tri, and multi/poly) structures. The unknown words in the selected corpus should be handled first in the class. If needed, the teacher transcribes the words for the students. These words will be repeated by individual, pair or group, after the exhortations avoiding parroting style of articulation.

\section{Corpus:}

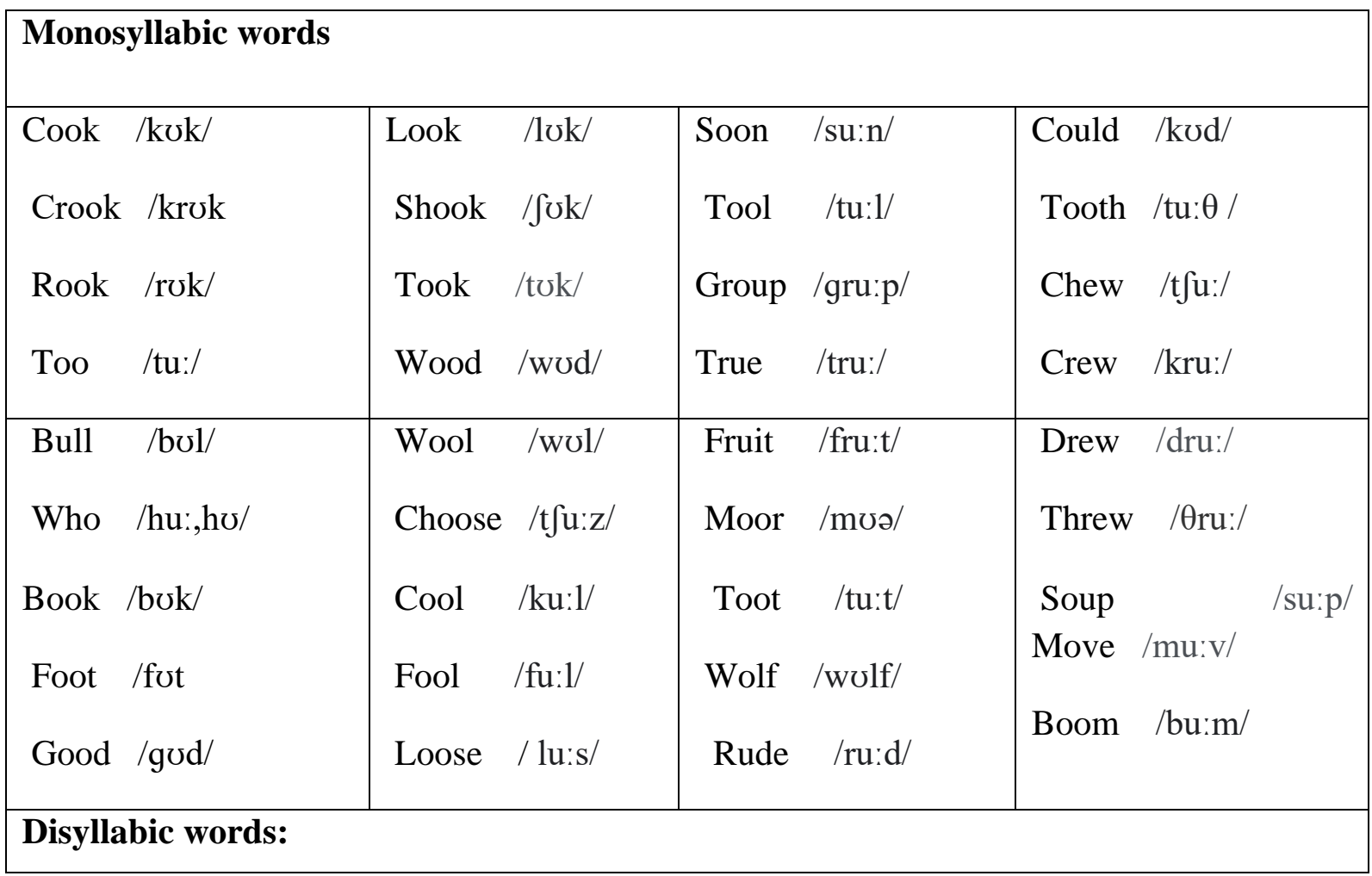




\section{Trisyllabic word:}

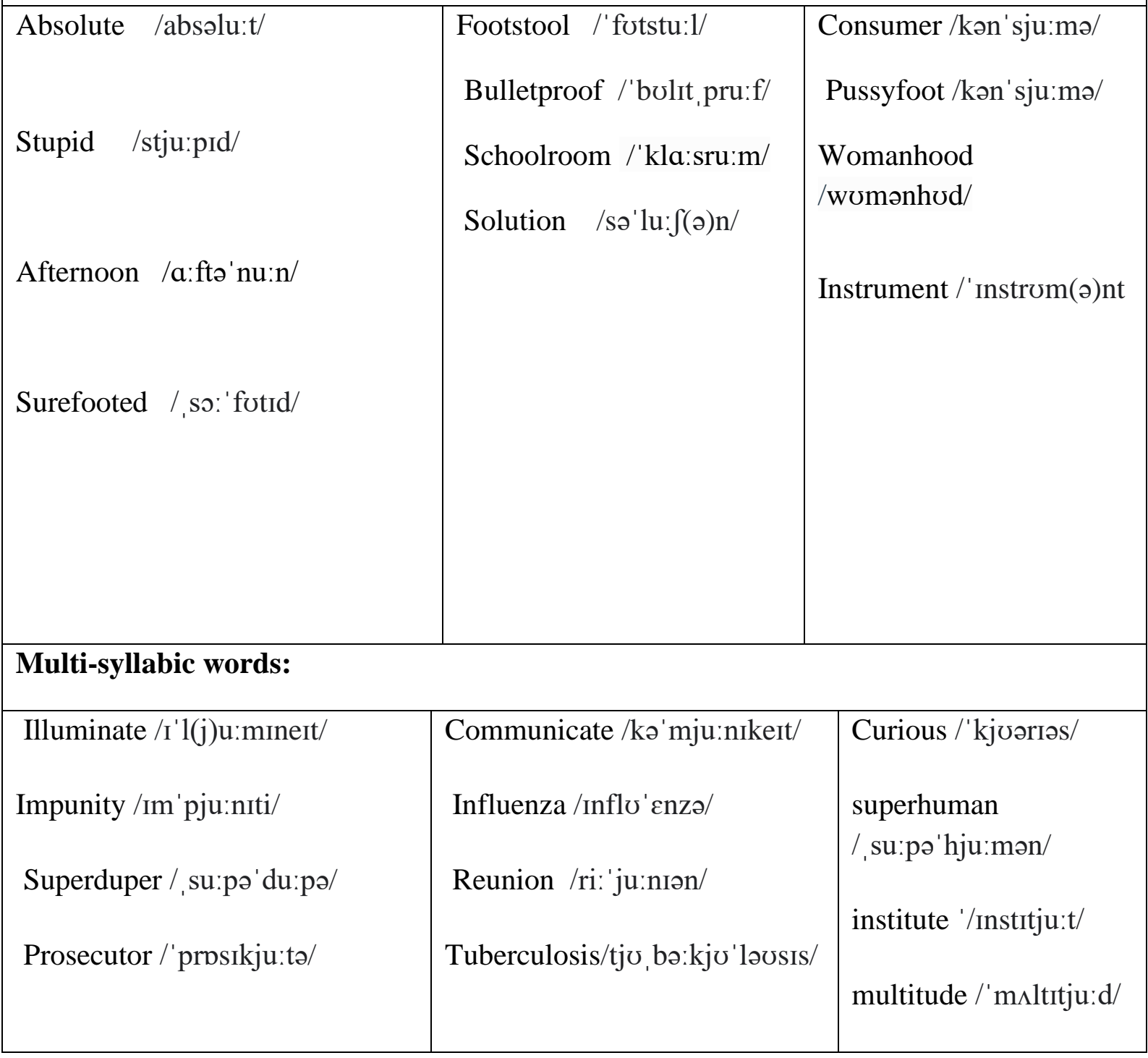

Meaning and transcription of unknown words: 


\begin{tabular}{|l|l|l|}
\hline Crook & /krok/ & $\begin{array}{l}\text { bad, unpleasant, or unsatisfactory. A person who is dishonest or a } \\
\text { criminal. }\end{array}$ \\
\hline Toot & /tu:t/ & a short, sharp sound made by a horn, trumpet, or similar instrument. \\
\hline Lew & $/$ 'lü / & now dialectal British : moderately warm : lukewarm \\
\hline Brew & /bru:/ & make (beer) by soaking, boiling, and fermentation \\
\hline Boom & $/$ bu:m/ & a loud, deep, resonant sound \\
\hline Hoodoo & $/ /$ hu:du:/ & $\begin{array}{l}\text { a run of bad luck associated with a particular person, group, or } \\
\text { activity }\end{array}$ \\
\hline Impunity & $\begin{array}{l}\text { /Im'pju: } \\
\text { niti/ }\end{array}$ & $\begin{array}{l}\text { exemption from punishment or freedom from the injurious } \\
\text { consequences of an action }\end{array}$ \\
\hline Brook & /brok/ & a small stream \\
\hline Broom & $/$ bru:m/ & a long-handled brush of bristles or twigs, used for sweeping. \\
\hline
\end{tabular}

Teacher: Dear students, it's the time for discussing the rule now, please, be careful and listen to me attentively. To pronounce / $\mathrm{u} /$ sound, our lips become rounded, the back of the tongue goes fairly high and it remains tense. So it is a short vowel. To pronounce /u:/ sound, our lips also becomes round and the back ( further back than $/ \mathrm{u} /$ ) of the tongue goes fully high ( very high) and it remains tense. So it is a long vowel. The [u] sound is a short back high rounded vowel in English. We hear it in could, would, look, push, put etc and the /u:/ sound is a long back high rounded vowel. We can identify it in these words: rouge, root, tool, shoe, food, do etc ( Rajimwale, 1999). You will be more clear about the articulation of /u/ and /u:/ sound from the following image.

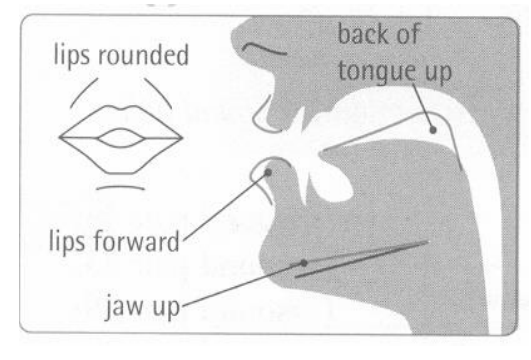

Figure 1 : Image of articulating /u/ and /u:/ sound

\section{Language Game with rhyme:}

Teacher: students come anyone of you and recite the poems before the class.

other students will listen to him carefully and try to imitate him. 


\section{Minimal pairs:}

The heart of any drilling or demonstrating of specific sound features is contrast of one kind or another. The most efficient way of showing contrast is by minimal pairs. Any pair of words or phrases or sentences where there is only one feature to distinguish them is a minimal pair. e.g. part, port: a tack, a tag (Broughton et al.,1980:63). The teacher highlights the minimal pairs showing the /u/ and /u:/ differences; if there are unknown words in the minimal pairs, teacher carefully handles them first. After the exhortations, he has the words repeated in single, pair or group. "A minimal pair is a pair of words that differ in a single phoneme. Minimal pairs are often used to show that two sounds contrast in a language. For example, we can demonstrate that [s] and [z] contrast in English by adducing minimal pairs such as sip and zip, or bus and buzz. Since the only difference in these words is the [s] vs. [z], we conclude that they belong to distinct phonemes. However, a similar test would show that [a:j] and [Aj] are distinct phonemes in English, since writer and rider appear to be minimal pairs distinguished in their second elements, not their fourth," (McGilvray 2005). In short, minimal pairs serve as tools to establish that two or more sounds are contrastive. A difference in sound means a difference in meaning, notes Harriet Joseph Ottenheimer, and thus a minimal pair is "the clearest and easiest way to identify phonemes in a language," (Ottenheimer, 2012). 


\begin{tabular}{|c|c|c|c|}
\hline$/ \mathrm{u} /$ & /u:/ & $/ \mathrm{u} /$ & /u:/ \\
\hline Full /ful/ & Fool /fu:1/ & Luke /lu:k/luk/ & Look /lu:k/ \\
\hline Pull /pul/ & Pool /pu:1/ & Should /Jud/ & shooed / $\mathrm{ju}: \mathrm{d} /$ \\
\hline Could /kud/ & Cooed /ku:d/ & stood /stud/ & stewed /stu:d/ \\
\hline would /wud/ & Wooed /wu:d/ & cook /kuk/ & kook /ku:k/ \\
\hline bull /bul/ & Boole /bu:1/ & suit /sut/ & soot /su:t/ \\
\hline hood /hud/ & Who'd /wu:d/ & wood /wud/ & wooed /wu:d/ \\
\hline good /gud/ & Gooed /gu:d/ & Moon /mun/ & Noon /nu:n/ \\
\hline soot /sut/ & Suit /su:d/ & flew /flu:/ & blue /blu:/ \\
\hline kooky /kui/ & Cookie /ku:ki/ & too /tu:/ & zoo /zu:/ \\
\hline blew /blu/ & Clue /klu:/ & new /nju:/ & Sue /su:/ \\
\hline toon /tun/ & Soon/su:n/ & mule /mju:l/ & Mute /mjut/ \\
\hline toot/tut/ & Boot /bu:t/ & tune /tun/ & Dune /dju:n/ \\
\hline
\end{tabular}

Tongue twisters:

After counseling, the teacher will endeavor to use tongue twisters in the class for practice in single, group, or Choir. The teacher plays a vital role to improve the audiomemory of the students during the repetitions without boring them.

\section{Tongue twister with /u/ and /u:/sound}

He too, took two looks.

The cookbook recommended bamboo shoots.

The bloody boots were looted.

The good groom flooded the room.

The football hooligans looked gloomy.

Oops, look it's already noon.

She cooked the soot covered roots. 
He stood on a spoon and looked at the moon.

The cool wood was good food.

The woodpeckers at the zoo used wool for their room.

https://englishxp.co.uk/tongue-twisters/u-oo-tongue-twisters/

\section{Tongue twister with /u:/sound}

A Tudor who tooted a flute

Tried to tutor two tooters to toot.

Said the two to their tutor,

"Is it harder to toot

or to tutor two tooters to toot?" (https://languageavenue.com/teachers/teaching-ideas/english tonguetwisters/item/long-vowel-sound-u)

\section{Chain drill:}

Chain drill activity is one of the methods that can be used in teaching speaking. Larsen-Freeman (2000:48) stated "A chain drill gets its name from the chain of conversation that forms around the room as students, one- by one, ask and answer questions of each other". Chain drill can encourage the improvement of two abilities in one technique on teaching speaking that are students listening and speaking ability ( sintuwumaroso JET, Vol. 3, No. 1, August 2017).

Teacher: Let us sit in a circle and begin the chain drill to articulate /u:/ sound properly. It allows some controlled communication, even though it is limited.

Chain drill will be practiced in the following way:

a. Student 1 asks student 2 a question.

b. Student 2 answers and asks student 3 the same question.

c. Student 3 answers and asks student 4 a question.

$\mathrm{d}$, Student 4 answers the question. In this way, the drilling will be going on in a cycling way.

For example,

$\mathrm{S}^{1}$ asks $\mathrm{S} 2$ : do you have any book?

$\mathrm{S}^{2}$ answers Yes I do" or Yes, I have a book. And he asks the same question to $\mathrm{S}^{3}$.

$\mathrm{S}^{3}$ answers and asks $\mathrm{S}^{4}$, does he (she) have his (her) book? referring to $\mathrm{S}^{2}$.

$S^{4}$ : I am not sure. But he took a book from Luther Yesterday. Turning to $S^{5}$, he asks him, do you know what type of book it is?

$S^{5}$ : It is a book for preparing soup with mushroom. Turning to $S^{5,}$ do you choose to eat this soup? 
$S^{6:}$ Yes, I do.

Chain drill should be broken frequently. After six to eight students will participate in a chain of question or statement and response at one of the room (Finocchiaro, 1969:68).

\section{Cliché words:}

T: According to Demirezen, Cliché words are helpful for articulating any sound and to defossilize problem causing sound in non native speakers. Cliché word is one kind of drill in Audio-Articulation method. As cliché words are mostly familiar to the learners they can easily articulate the sound of the target language. Some cliché expressions are as follow,

\section{Story with /u/ and /u:/ sound}

Jud has a Jukebox in his room.

Luke likes to play with the Jukebox, but he will not pay.

"My Jukebox is not free," says Jud. "If you want tunes, you must pay."

"But I am your bud, ”says Luke. “ Must I pay to play a tune?"

"Yes, you must," says Jud. My tunes are good. If you want cool tunes, you must pay first."

"You are too rude," says Luke. "I will listen to tunes at home.'

"Wait, Wait!" says Jud. "You can stay! The tunes are free! I don't mean to be rude. I am just poor! https://www.stickyball.net/pdfs/phonics/book\%203/long\%20u\%20story.pdf

\section{SUBSTITUTION DRILL}

Substitution drill is a classroom technique used to practice new language. It involves the teacher as the first modeling a word or a sentence and the learners repeat it. The learners then substitutes one or more key words, or changes the prompt. (Sutrisno, 2013). This is an inherent characteristic of drill as it is defined: "a type of highly controlled oral practice in which the students respond to a given cue" (Matthews, Spratt \& Dangerfield, 1991, p.210). Pillai \& Narasimharao, (1985) stated that sometimes substitution introduces into one frame necessitated a change of one or more segments of the sentence. Substitution drill may be of various types according to the mechanism of operation and they are:

\section{a. Simple substitution/Single slot substitution}

The teacher presents the basic structure that needs to be practiced by the learners. A cue word to substitute in a slot is given and the learner is expected to give the new sentence retaining the same pattern. This is a simple substitution in the sense that neither the cue word nor the structure undergoes any change. Some examples are given by the teacher himself to illustrate and then the learner is asked to proceed on similar lines (Maharida, 2014).

Example: the teacher said, "Mithu is a good boy".

The students repeat "Mithu is a rude boy" and "Mithu is a crude boy". 


\section{b. Substitution in different slots/Mixed slot substitution}

The substitution will be simple but in different slots with different grammatical categories. The learner has to know the grammatical category of the cue words. However, more complex items, such as gender, number, etc., will not be introduced (Maharida, 2014).

Example, the teacher said. "he eats a food".

The students repeat "he eats a fruit " and "he takes soup".

\section{c. Substitution that forces a change in the structure}

To enable the learners to know that substitution in a slot sometimes forces a change in the structures. Procedure: When the learners substitute the cue words, the filler sentence needs some changes, like changes in gender, person, number, etc. (Maharida, 2014).

Example, the teacher said "she speaks the truth".

The students repeat " he speaks the truth" and "they speak the truth".

\section{d. Substitution that calls for a change in the cue}

In this type of substitution, the cue word itself is to be changed before substituting according to the requirement of the filler sentence. The cue word will be given and the learner will change it according to the requirements before substitution (Maharida, 2014).

Example, the teacher said "He should chew the chewing gum".

The students repeat "He should put the broom." and "He must shoot the wolf."

\section{e. Multiple slot substitution}

Instead of substituting in only one frame, the learner has to do it in different frames without affecting any change in the grammatical structure (Maharida, 2014).

Example, the teacher said "There are many bulls in the wood".

The students substitute "there are many fools in the group" and the second "there are many roots in the bush".

\section{f. Progressive slot substitution/Moving slot substitution}

The learner must remember the preceding sentence in which he has substituted and he must make a new one according to the cue word given. The pattern of substituting in each succeeding slot is maintained (Maharida, 2014).

Example, the teacher said "He could look at the bullet".

The students substitute "Zulu could look at the bullet" (Maharida, 2014). 


\subsection{Replacement Drill}

Teacher: Dear students, let us replace / $\mathrm{u} /$ sound by /u:/ and vice versa in the following words. To produce /u/ sound our lips round a little and we have to push them forward to produce this sound. The back of our tongue and our jaw will go up a little. To produce /u:/ Sound our lips round and we have to pull the front of our tongue back, while lifting our jaw a bit to produce this sound.

Teacher will produce /u/ sound in the words and ask the students to replace /u/ sound by /u:/ and produce another word.

\begin{tabular}{|ll|l|l|l|l|}
\hline \multicolumn{3}{|c|}{ Teacher } & \multicolumn{3}{c|}{ Students } \\
\hline To /tu/ & Foot /fut/ & Too /tu:/ & Who /hu:/ \\
Bhrow /Orəo/ & Book /buk/ & Through /Oru:/ & Rude /ru:d) \\
Put /pot/ & Cook /kuk/ & Move /mu:v/ & Food /fu:d/ \\
& & Group /gru:p/ & Toot /tu:t/ \\
& & & & Cartoon /ka:tu:n/ \\
\hline
\end{tabular}

\subsection{Recognition drill /Independent Learning}

Teacher: Dear students, now you yourselves will read the sentences and specially highlight the boldfaces words in the sentences to test yourselves whether you're pronouncing $/ \mathrm{u} /$ and $/ \mathrm{u}$ :/ sound correctly or not.

Book is our best friend.

She went home on foot.

The weather is very cool.

Fool rushes where angel fears to tread.

He saw a wolf in the wood.

I heard a boom and rushed the spot.

I need some wool to complete the coat.

Brush your tooth in every afternoon.

The crew threw the chewing gum in the pool.

We shook hands and took our seats. 
The main focus of this article is to implement Audio-Articulation Method in Bangladeshi EFL class room to rehabilitate /u/উ/ sound and to articulate /u: / sound correctly by the tertiary level students. The author, in his experience observed that distinct Bangla sounds have been fossilized in the Bangladeshi adult speakers of English. These fossilized Bangla sounds have become a barrier for them to produce and articulate certain English phonemes. That is why, their English speech has lost the comprehensibility level to the listeners. Now it is a crying need to make the learners aware of the phonological fossilization of Bangla sounds and help them to defossilize the problem causing core sounds of English for producing intelligible pronunciation. Thus, the author attempts to create this pragmatic and innovative lesson plan. A well designed lesson plan is indispensable to conduct the class effectively within scheduled time. An empirical and contextualized lesson plan helps the students to participate actively in the class in a friendly environment. As Audio Articulation Method is a new method in Bangladesh, a well-organized lesson plan is very much needed to apply this method to handle the phonological errors in English pronunciation of Bangladeshi learners. This method has introduced different kinds of drills which are very much helpful to defossilize the problem causing Bangla sounds in English pronunciation of Bengali students in class hour. By practicing these drills, listening to the teacher's pronunciation and imitating his activities, the students will be able to produce comprehensible sound of English and their pronunciation will be apprehensible to the listeners.

\section{CONCLUSION}

Drilling, the main issue of Audio articulation method is a fruitful technique to defossilize the problem causing core sound of English in the pronunciation of Bangladeshi EFL students. But there must be a balance between class hour and teaching materials. Hence, a properly designed lesson plan according to Audio articulation method (AAM) is essential to handle the fossilized errors in the learners. If the teachers apply the Audio-Articulation Method through a pedagogically designed lesson plan and give corrective feedback to phonological fossilization in English pronunciation of Bangladeshi adult speakers of English in the class room, fossilized sounds will be rehabilitated to a great extent.

\section{REFERENCE:}

Amanullah, S. M. (2009). A guide to correct speech. Albatross Publication, Dhaka-1205

Baker, A. (1996). Ship or Sheep? An intermediate pronunciation course. New York. Cambridge University press.

Broughton, G. \& Others. (1980). Teaching English as a Foreign Language. (2nd ed). London \& New York: 203203 Routledge Education Book.

Demirezen, M.(2005). Rehabilitating a Fossilized Pronunciation Error: the $/ v /$ and $/ w /$ Contrast by Using the Audio Articulation Method in Teacher Training in Turkey. 
Journal of Language and Linguistic Studies Vol. 1, No.2.Retrieved from https://dergipark.org.tr/tr/download/article-file/104662

Deogirkar, S.V. ( 2013). On Teaching Pronunciation as an Essential Soft Skill to Overcome Odds! https://www.academia.edu/15681936/

JAVID, L. M. (2020). Investigation of the Relationship(s) between using Substitution Drill Technique and Memory Permanency in Adult EFL Learners. International Journal of Advances in Science Engineering and Technology, ISSN(p): 2321 -8991, ISSN(e): 2321 -9009 Volume-8, Issue-3, Jul.-2020, http://iraj.in

Gilakjani, A. P. (2012). A Study of Factors Affecting EFL Learners' English Pronunciation Learning and the Strategies for Instruction. International Journal of Humanities and Social Science Vol. 2 No. 3; February 119

Joseph, T. C. et al. ( 2019)). Role of Proper English Pronunciation in Projecting a Better Personality. Available from: https://www.researchgate.net/publication/330555188_Role_of_Proper_English_Pron unciation_in_Projecting_a_Better_Personality

Lantu, I. P. ( 2017). CHAIN DRILL TECHNIQUE IN TEACHING SPEAKING. sintuwumarosoJET, Vol. 3, No. 1,

Maharida. (2014). USING SUBSTUTION DRILL TECHNIQUE TO IMPROVE STUDENTS' PRONUNCIATION ABILITY. English Education Department, Faculty of Teacher Training and Education Muhammadiyah University of Makassar Retrieved from https://media.neliti.com > media > publications > 2...

Nordquist, R.( 2020). Phoneme vs. Minimal Pair in English Phonetics. Retrieved from https://www.thoughtco.com/minimal-pair-phonetics-1691392

Otlowski. M. (1998). Pronunciation: What Are the Expectations?

The Internet TESL Journal, Vol. IV, No. 1, January 1998 http://iteslj.org/

Pardede, P. (2022). The Role of Pronunciation in a Foreign Language Program. Universitas Kristen Indonesia, Jakarta. https://www.researchgate.net/publication/337276730_The_Role_of_Pronunciation_i n a Foreign Language Program

Rajimwale, S. (1999). Elements ofgeneral linguistics.Volume-1, 2. New Delhi Rama brothers (Publishing Division). 2629/4, Bank Street, Korol Bagh-110 005.

SENOWARSITO \& ARDINI, S. N. (2019). Phonological Fossilisation of EFL Learners: The Interference of Phonological and Orthographic System of L1 Javanese.The Southeast Asian Journal of English Language Studies -Vol 25(2): $74-85$ http://doi.org/10.17576/3L-2019-2502-06 
Uddin, M. (2021). Pedagogical implication of Audio-Articulation Method to defossilize /e/V sound in English pronunciation of Bangladeshi EFL learners. International Journal of Linguistics and Translation $\quad$ Studies, 2(4), https://doi.org/10.36892/ijlts.v2i4.166

Wei, X. (2008). Implication of IL Fossilization in Second Language Acquisition. Graduate School of Foreign Language, Beijing Language and Culture University.10\#215, 15 Xueyuan Road, Beijing 100083, China.

\section{About the Author}

Mohammad Nashir Uddin is a PhD candidate in TESOL program at International Islamic University, Malaysia. He has 15 years of experience in teaching English as a second/foreign language. His research interests include fossilized sounds in English pronunciation. 